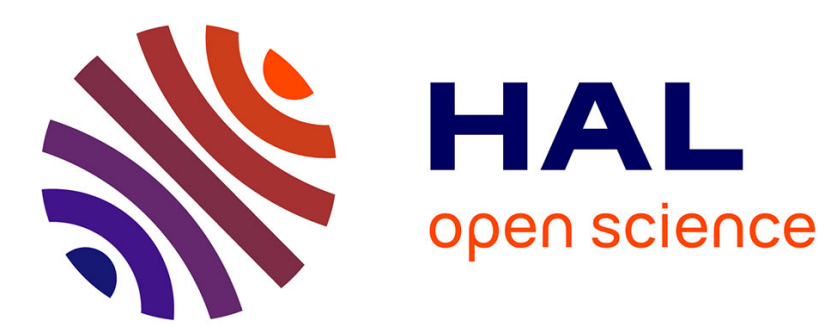

\title{
A cesium cell with laser beam multipass
}

M. A. Bouchiat, L. Pottier, Gérard Trénec

\section{To cite this version:}

M. A. Bouchiat, L. Pottier, Gérard Trénec. A cesium cell with laser beam multipass. Revue de Physique Appliquée, 1980, 15 (3), pp.785-788. 10.1051/rphysap:01980001503078500 . jpa-00244788

\section{HAL Id: jpa-00244788 https://hal.science/jpa-00244788}

Submitted on 1 Jan 1980

HAL is a multi-disciplinary open access archive for the deposit and dissemination of scientific research documents, whether they are published or not. The documents may come from teaching and research institutions in France or abroad, or from public or private research centers.
L'archive ouverte pluridisciplinaire HAL, est destinée au dépôt et à la diffusion de documents scientifiques de niveau recherche, publiés ou non, émanant des établissements d'enseignement et de recherche français ou étrangers, des laboratoires publics ou privés. 


\title{
A cesium cell with laser beam multipass
}

\author{
M. A. Bouchiat, L. Pottier and G. Trenec \\ Laboratoire de Physique de l'E.N.S., 24, rue Lhomond, 75231 Paris Cedex 05, France
}

(Reçu le 19 octobre 1979, accepté le 26 novembre 1979)

\begin{abstract}
Résumé. - On décrit une cellule conçue pour étudier la lumière émise (p. ex. par fluorescence) par une vapeur de césium excitée par un faisceau laser pour lequel l'absorption est négligeable. Un multipassage efficace du faisceau laser accroît de deux ordres de grandeur l'intensité lumineuse émise, en même temps qu'il inhibe par un large facteur certains signaux indésirables. Cette cellule est actuellement utilisée pour rechercher dans le césium une violation de parité induite par les courants faibles neutres; elle convient également pour du pompage optique sur des raies peu absorbées.
\end{abstract}

\begin{abstract}
We describe a cesium cell designed to study the light emitted (e.g. by fluorescence) by cesium vapour excited by a laser beam for which the absorption is negligible. Efficient multipass of the laser beam increases the emitted light intensity by two orders of magnitude while suppressing some undesired signals by a large factor. This sample cell is currently used in a search for weak neutral current parity violation in cesium; it is also suitable for optical pumping on weakly absorbed lines.
\end{abstract}

1. Introduction. - The initial motivation of the present work is the search for the parity violation induced in atoms by weak neutral currents [1]. The particular experiment considered here is the study of the highly forbidden $6 \mathrm{~S}_{1 / 2} \rightarrow 7 \mathrm{~S}_{1 / 2}$ transition in atomic cesium [2]. In this experiment Cs atoms are submitted to a d.c. electric field $\mathbf{E}_{0}$ along $\mathrm{O} x$ (see Fig. 1) and excited by a circularly polarized laser beam tuned for the forbidden transition (5 $394 \AA)$ and directed along $\mathrm{O} y$. The fluorescence light corresponding to the $7 \mathrm{~S}_{1 / 2} \rightarrow 6 \mathrm{P}_{1 / 2}$ decay $(1.36 \mu)$ is monitored in the $\mathrm{O} z$ direction and its circular polarization ratio $\xi_{\mathrm{f}}$ is measured. The predicted parity violation should manifest itself as a small change of $\xi_{\mathrm{f}}$ when the circular polarization $\xi_{\mathrm{e}}$ of the exciting beam is reversed :

$$
\Delta \xi_{\mathrm{f}}=\xi_{\mathrm{f}}\left(\xi_{\mathrm{e}}=+1\right)-\xi_{\mathrm{f}}\left(\xi_{\mathrm{e}}=-1\right) \sim 10^{-6} .
$$

The considered transition is highly forbidden : in zero electric field its oscillator strength is only $f \sim 4 \times 10^{-15}$ ! In non-zero field this value is increased by Stark effect but remains still extremely small (e.g. $f \sim 10^{-10}$ for typical $E_{0}=300 \mathrm{~V} / \mathrm{cm}$ ). Thus the absorption of the laser beam is negligible; therefore the transmitted beam can in principle be used again, so as to increase the fluorescence intensity.

From a purely optical point of view, this can be achieved very easily by placing the cesium vapor between two spherical mirrors facing each other and

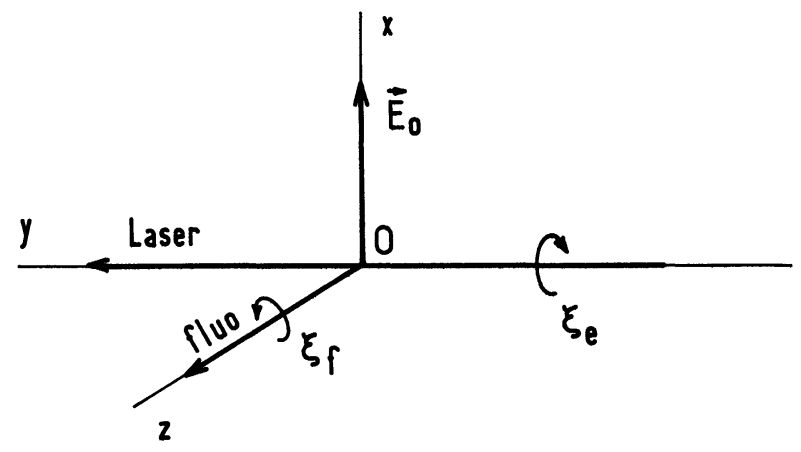

Fig. 1. - Experimental configuration for the parity violation experiment.

having the mode-matched laser beam perform a number of passes forward and backward between them [3]. The beam comes in through a small hole drilled in one of the mirrors; after an even number of passes (4 on figure 2 for the sake of simplicity; typically 140 to 160 in our real set-up) the beam comes back to the hole and escapes.

However, placing cesium vapor at a pressure of 0.1 torr in this optical system presents some technological difficulties. The purpose of the present paper is to describe the solutions that were adopted.

2. Interest of a multipass. - 1) Let us first underline that this optical device (which we call hereafter 


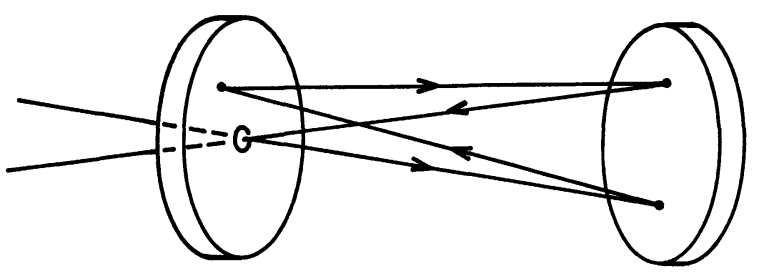

Fig. 2. - Multipass of a laser beam between two spherical mirrors. In our real system the number of passes is $\sim 150$.

a multipass) is not a Fabry-Perot interferometer (FPI), since the various passes do not coincide what is more, they do not overlap - thus they cannot interfere. A consequent advantage of the multipass as compared with the FPI is that the spacing between the mirrors is not at all critical : while the spacing of the FPI should be defined to within a fraction of the wavelength divided by the finesse (say, $5 \AA$ !) the spacing of the multipass has nothing to do with the wavelength, since there are no interferences; it is connected only with macroscopic parameters (beam diameter, input hole diameter, mirror curvature). As a result, large spacing fluctuations (as large as $0.1 \mathrm{~mm}$ in our set-up) are unimportant, so that the multipass can be used, even in an oven, without any problem of thermal stability.

2) An obvious advantage of the multipass is to increase the effective laser intensity by some large factor, equal to the number $n$ of passes in the case of ideal mirrors with reflectivity $r=1$. For real mirrors the gain factor is

$$
G=1+r+r^{2}+\cdots+r^{n-1}=\left(1-r^{n}\right) /(1-r) .
$$

(For example, in our set-up $r \sim 0.998, n \sim 150$ and $G \sim 125$.

3) Another advantage of the multipass is found in the fact that each forward pass is followed by a backward pass in a nearly opposite direction (provided the mirror spacing $L$ is large compared with the mirror diameter $D$ ) and with a nearly equal intensity (provided the reflectivity of the mirrors is good); the backward pass thus corresponds to nearly opposite photon momentum but nearly equal photon angular momentum. Therefore signals that depend only on the photon momentum are nearly cancelled, while those that depend only on the photon angular momentum are nearly doubled; as a result, the former are strongly suppressed as compared with the latter : in our real cell the relative suppression factor is equal to several hundreds. This is a crucial advantage in the case of our parity violation experiment, since many possible systematics can be shown to belong to the category of suppressed signals (in contrast with the parity violation signal under search) : e.g. systematics associated with a stray magnetic field along the laser beam [4].

The conservation of the photon's angular momen- tum in the multipass also makes it possible to orient an atomic vapor (of low absorption) in a circularly polarized multipass beam. (This is also used in our experiment.)

4) An important question is : how is the polarization altered after such a large number of reflexions? We have no general answer to this question; however, measurements performed with our particular geometry and coatings have shown that circularly polarized light remains circularly polarized to better than $99 \%$ after the multipass, which is quite sufficient for our practical purpose. This good conservation of polarization is probably due to the quasi-normal incidences $\left(0.7^{\circ} \leqslant i \leqslant 4^{\circ}\right)$ in our geometry.

3. Realization of a multipass cell for cesium. 3.1 Global PReSEntation (see Fig. 3). - The cell basically consists of a long glass tube with a stainlesssteel set-up at each end. The center part of the glass tube - the observation region - contains the d.c. field plates and the cesium reservoirs; it is heated to about $200^{\circ} \mathrm{C}$ (Cs vapor pressure $\sim 10^{-1}$ torr) in an oven. The steel ends are essentially adjustable mounts for the mirrors. The materials ( 747 glass ; $18 / 10$ stainless steel; tungsten or molybdenum for the field plate rods) are insensitive to cesium.

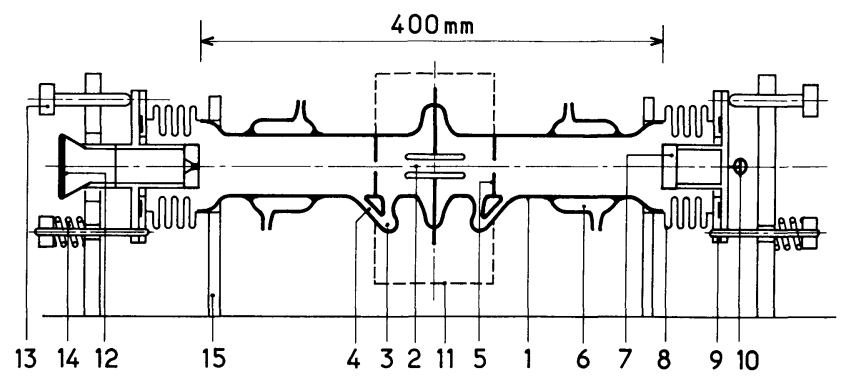

Fig. 3. - Overall scheme of the multipass cesium cell (1: glass tube ; 2 : observation region with electric field plates; 3 : cesium reservoirs; 4 : return tubes; $5:$ diaphragms; 6 : water coolings; 7 : mirrors ; 8 : bellows ; 9 : flanges with copper rings ; 10 : repumping valve; 11 : oven $; 12$ : entrance window $; 13:$ mirror adjustment screws; $14:$ springs; $15:$ stand).

3.2 PART-BY-PART DESCRIPTION. - Let us now review the various conditions to be fulfilled and the corresponding solutions retained in our design.

3.2.1 Internal mirrors. - Because the exciting laser beam is polarized circularly, we have to use normal windows rather than Brewster ones. In order to prevent the corresponding reflection losses from killing the efficiency of the multipass, these windows have to be located outside the pair of mirrors; i.e. the mirrors should be placed inside the cell. (A cell with internal mirrors appeared to be more realizable than a - vacuum-tight - celle with windows antireflection coated on both sides.)

3.2.2 Adjustable mirrors. - The setting of the multipass requires the position and orientation of the 
mirrors in the cell to be adjustable to within about $0.1 \mathrm{~mm}$ and $1 / 4$ of a degree respectively. This is achieved by mounting the mirror holders on flexible stainless-steel bellows. The fixed (central) end of each bellow is clutched in the stand ; the movable (extreme) end is maintained in touch with three positioning micrometer screws by three springs fastened in the stand. Thus the atmospheric pressing force $(\sim 30 \mathrm{~kg})$ that would else squash the bellow, is compensated by the springs and the stand but is not felt by the glassware.

The bellows are soldered to the glass tube. Each mirror holder is screwed (with a copper ring) on a steel flange soldered to the bellow; removing the holder allows easy mirror replacement and opens access into the cell.

3.2.3 «Cool» mirrors. - At the experiment's temperature $\left(200^{\circ} \mathrm{C}\right)$ the dielectric coatings of the mirrors turn out to be rapidly destroyed by cesium vapor. To avoid this the cell is given a long shape; only the center (observation region) is heated; the mirrors are placed in the water-cooled ends and protected by a buffer gas (helium in our experiments).

3.2.4 Return tubes. - In order to provide some regeneration of the cesium reserve, between the oven $\left(200{ }^{\circ} \mathrm{C}\right)$ and the water-cooled ends $\left(10\right.$ to $\left.20^{\circ} \mathrm{C}\right)$ there is a sufficiently large warm region where the vapor will condense as liquid droplets (melting point of $\mathrm{Cs}: 28^{\circ} \mathrm{C}$ ) that will now and then suddenly unite in a liquid stream that flows down the wall. A simple slant tube then brings this cesium back to the reservoir. The vapor that succeeds in reaching the cool regions $\left(<28{ }^{\circ} \mathrm{C}\right)$ condenses there in the solid state and is lost cesium.

3.2.5 Dynamical vapor pressure regime. - In the observation region the vapor pressure does not take the saturation value, but some smaller value resulting from the dynamical equilibrium between the source term (vapor inflow from the reservoirs) and the loss term (diffusion towards the cool ends). A naive means of compensating this pressure defect would be to increase the temperature : but this would increase simultaneously the black-body radiation from the oven, which is the main source of noise in our experiment. A better policy is to improve the thermal coupling between oven and cell, by having the heating parts fit the shape of the cell or filling the spaces with a heat-conducting " fluid" (small shot). In addition, stainless steel diaphragms just large enough for the multipass reduce the diffusion towards the cool ends. We finally obtain a pressure in the range between the saturation pressure and one third of it, depending on how much cesium remains in the reservoirs.

3.2.6 Repumping facility. - The cell is provided with a ultra-vacuum valve and a pumping connection, so that the nature or pressure of the buffer gas can readily be changed.
3.2.7 Oven. - The central part of the cell (observation region) is heated in a two-heater oven : the lower heater (floor) directly heats the reservoirs through small shot filling; the upper heater (ceiling) rides close above the cell body. Both heaters are temperature stabilized. The bottom temperature is slightly higher than the top one, yet without contaminating the observation region with cesium condensation.

3.2.8 Choice of the parameters. - In this paragraph we will explain how to choose the values for the various parameters : dimensions of the cell, curvature of the mirrors, size of the beam entrance hole, etc.

- The mirror spacing $L(40 \mathrm{~cm})$ is obtained by adding reasonable values for the lengths of the various parts : observation region, warm regions, water coolings;

- Once the spacing is chosen the mode-matching condition then establishes a relation between the curvature of the mirrors and the diameter of the laser spots on the mirrors; for the mirrors to accomodate a maximum number of spots (i.e. of passes) without overlapping, the spot size should be minimized, which is realized when the curvature radius $R$ of the mirrors is equal to the spacing (confocal or nearconfocal situation). The corresponding minimal spot diameter $d_{\min }$ is then

$$
d_{\min }=2 \sqrt{\lambda L / \pi}
$$

(i.e. $0.52 \mathrm{~mm}$ in our case for $\lambda=0.54 \mu$ );

- The diameter $d_{\mathrm{h}}$ of the beam entrance hole should then be chosen somewhat larger than the diameter $d_{\min }$ of the entering and outgoing beam, so as to avoid scattering from the hole edge. Yet it should not be taken too large since the size of the hole puts an upper limit to the number of passes : this is because the distance between the hole center (entrance " spot ») and the next spot has to be large enough for the latter spot not to overlap the hole. In our case a value $d_{\mathrm{h}}=1 \mathrm{~mm}$ appears to be a good choice. Note that since the beam comes in with some finite incidence $\theta$ (in our case $\sim 3 \times 10^{-2} \mathrm{rad}$ ) with respect to the axis and goes out symmetrically, it is necessary to drill in the (thick) mirror a conical hole, as shown on figure 4.

- The diameter $D$ of the mirror is chosen independently on the previous parameters. Increasing the size of the mirrors will increase the number of spots (i.e. of passes) that can be accommodated ; the limitation is that this will accordingly increase the diameter of the bundle of beams and of the observation region which has to be imaged onto the detector. We have chosen a value $D=30 \mathrm{~mm}$. Besides, we adjust the mirrors so that the ellipse, locus of the spots on each mirror (cf. Ref. [3]) is almost degenerated into its long axis; the bundle of beams of the multipass is then almost degenerated into a flat ribbon of light. 


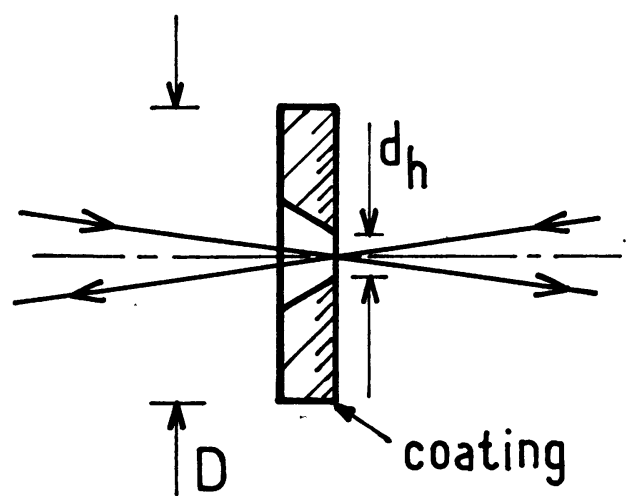

Fig. 4. - Input mirror of the multipass. Note the conical hole allowing beam input and output under finite incidence.

The detector that monitors the fluorescence is placed in the plane of the ribbon.

3.2.9 Filling the cell. - First the mirror holders (with the mirrors) are assembled with their copper rings to the cell, which is then pumped and outgassed at the highest temperature permitted by the mirror coatings $\left(\$ 300^{\circ} \mathrm{C}\right)$. Then the reservoirs are filled with cesium. This can be done on the pumping bench by distillation in the vacuum (through additional filling tubes appended to the reservoirs) : yet it is difficult to prevent any cesium from reaching the mirrors and ruining them. A much safer method consists in opening the cell under inert atmosphere, in a glove-box [5] gently heated to about $30^{\circ} \mathrm{C}$ : feeding $5 \mathrm{~cm}^{3}$ of liquid cesium directly into each reservoir with a syringe is then straightforward. The glovebox also allows various repair operations (mirror replacement, cesium addition...) without complete cleaning and refilling.

Acknowledgments. - The authors express their thanks to SVT [6] for the realization of the glassware and metal-glass solders; and to the members of the mechanics workshop of the laboratory for the realization and soldering of the steel parts.

\section{References and footnotes}

[1] Bouchiat, M. A. and Bouchiat, C., J. Physique 35 (1974) 899 and 36 (1975) 493.

[2] Bouchiat, M. A. and Pottier, L., Phys. Lett. 62B (1976) 327.

[3] Herriott, D., KogelniK, H. and Kompfner, R., Appl. Opt. 3 (1964) 523.
[4] Bouchiat, M. A. and Poirier, M., J. Physique, to be published.

[5] Cesium requires $\mathrm{O}_{2}$ and $\mathrm{H}_{2} \mathrm{O}$ concentration not exceeding $1 \mathrm{ppm}$; a stainless steel glove-box with continuous gas cycling and epuration is practically compulsory.

[6] Société de Verrerie et de Thermométrie, 135, rue du Théâtre, 75015 Paris.

Commission paritaire $\mathrm{N}^{\circ} 57.920$ 